\title{
Ontologia e artes em Merleau-Ponty
}

\section{Ontology and arts in Merleau-Ponty's work}

\section{Luiz Damon Santos Moutinho}

Doutor em Filosofia pela Universidade de São Paulo, professor adjunto da Universidade Federal do Paraná (UFPR), Curitiba, PR - Brasil, e-mail: luizdamon@yahoo.com.br

\section{Resumo}

Procuramos discutir a ontologia indireta de Merleau-Ponty a partir do estatuto conferido por ele às artes. De início, vinculando o logos do mundo estético de que fala a ontologia ao tema da pintura, o que confere a esta uma significação metafísica. Depois, vinculando aquele mesmo logos ao sentido do trabalho do artista. Por fim, uma aproximação entre Sartre e MerleauPonty a propósito da pintura e da literatura: de um lado, a ontologia merleaupontiana interdita conferir ao objeto estético o estatuto de irreal, como o faz Sartre; de outro, ela interdita ainda, por meio de uma distinção entre parole parlante e parole parlée, o papel proeminente conferido por Sartre ao prosador.

Palavras-chave: Merleau-Ponty. Ontologia. Artes. Estética. Pintura. 


\section{Abstract}

The present paper discusses Merleau-Ponty's indirect ontology by looking into the status he assigns to the arts. First we relate the logos of the aesthetic world to the theme of painting, which thus gains a metaphysical significance. Next, we relate that same logos to the work of the artist. Finally comes a rapprochement between Sartre and Merleau-Ponty on the subjects of painting and literature: on one hand, Merleau-Ponty's ontology denies the aesthetic object the status of unreal (as opposed to Sartre), on the other hand, by distinguishing between parole parlante and parole parlée, it also opposes the prominent role Sartre gives to the writer.

Keywords: Merleau-Ponty. Ontology. Arts. Aesthetics. Painting.

\section{I}

É bem sabido que Merleau-Ponty, desde sempre, foi um crítico do "idealismo" - cartesiano, kantiano e husserliano (e que, para cada uma dessas versões do "idealismo", destacou uma face que apontava para sua própria superação. Assim, o idealismo cartesiano da segunda Meditação aponta para sua superação na sexta; o idealismo da primeira Crítica, na terceira; o de Ideias I, na Krisis). Essa crítica, por sua vez, se consuma em uma ontologia que se afirma, de partida, por um reconhecimento do "primado da percepção". Não se trata, é bom frisar, da ontologia à maneira de Heidegger, que Merleau-Ponty denomina "direta". Heidegger se torna um dos alvos do filósofo no momento em que a ontologia se torna, explicitamente, a alternativa buscada por ele: Heidegger, diz ele no curso de 1958-1959, "busca uma expressão direta do ser, do qual ele mostra, aliás, que não é suscetível de expressão direta. Precisaria tentar a expressão indireta, i.e. fazer ver o Ser através dos Winke da vida, da ciência etc." (MERLEAU-PONTY, 1996a, p. 148). Em outro momento, quando tece elogios à descoberta moderna da subjetividade, afirma: "o filósofo que hoje chora Parmênides e queria nos traduzir nossas relações com o Ser tais como elas foram antes da consciência de si, deve justamente à consciência de si seu sentido e seu gosto pela ontologia primordial" (MERLEAU-PONTY, 1985, p. 194). Não é o caso de retomar aqui todos os passos da crítica ao "idealismo" e a Heidegger e a ontologia que daí se segue. A título de indicação, 
parece-nos que o ser, em Merleau-Ponty, é o ser do fenômeno - não há em sua obra a questão do Ser enquanto Ser. Se essa ontologia vai se definindo como "indireta", é porque o ser do fenômeno é tal que ele não pode tornar-se objeto de tematização (BARBARAS, 1991, p. 362). A diferença entre o ser e o ente não poderá jamais ser absoluta. Esse resultado parece intimamente vinculado à recusa de superar o mundo da experiência a fim de determinar seu ser (BARBARAS, 1991, p. 357). Dupla recusa, portanto: do "idealismo" (mais particularmente, do "idealismo transcendental" de Husserl) e da "ontologia fundamental" de Heidegger. É para aí que parece convergir a fenomenologia de Merleau-Ponty, e é a abertura desse novo território que vai permitir a ele dar um estatuto inédito às artes, sobretudo à pintura. Nosso objetivo aqui é restrito: vincular o alcance desse estatuto à ontologia indireta de Merleau-Ponty.

\section{II}

A presença do tema da pintura na obra de Merleau-Ponty é indissociável de uma valorização do sensível (ou da recusa de superar o sensível a fim de investigar o seu ser ou de determiná-lo a partir de uma consciência constituinte). Essa valorização conduz Merleau-Ponty a um tema que lhe é próprio e desconhecido tanto da "ontologia fundamental" de Heidegger quanto do "idealismo transcendental" de Husserl. Ela vai culminar em um "Logos do mundo estético", necessário para que seja concedida às artes (no caso, principalmente a pintura) uma "significação metafísica". É preciso mostrar o que isso significa, se se quer compreender aquela presença.

O núcleo da questão gira em torno da intencionalidade noemática. Essa descoberta implica em que aquilo que se oferece à atividade transcendental, enquanto atividade espontânea, já é de algum modo categorialmente enformado. A atividade transcendental tem então, como pressuposto, formas já elaboradas no nível pré-lógico. É nesse ponto que Heidegger insiste em sua leitura de Husserl (HEIDEGGER, 1979). Ora, nesse nível, torna-se difícil identificar aquela atividade espontânea, e é esse pressuposto que vai impondo a Husserl o alargamento da noção de intencionalidade. O recuo para estratos mais baixos do que o dos juízos predicativos vai se impondo mais fortemente, de modo a fazer surgir - é essa a interpretação de Merleau-Ponty - um antepredicativo que não se reduza mais, por maiores que sejam os esforços, por mais profundas que sejam as reduções, a uma atividade do sujeito - ainda que se tratasse de uma atividade escondida, profunda, oculta, mas atividade. 
Haverá então, por isso mesmo, uma passividade da atividade, uma opacidade, um fundo, que nenhuma tarefa de constituição poderá dar conta. É essa opacidade, essa "sombra" do filósofo, que Merleau-Ponty explora. Daí o recuo ao mundo - ou melhor, à percepção. A verdadeira redução é aquela que vai até esse mundo categorialmente enformado, antepredicativo, pré-constituído. A filosofia passa a se consagrar então a essa nova figura do Logos, o "Logos do mundo estético", do mundo sensível. Não há ali juízos predicativos, mas uma experiência originária do mundo, mundo que não é pensado como polo de uma relação por meio da qual ele seria pura objetividade, mas mundo sensível de minha experiência, muda e discursiva, minha e dos outros, articuladas por uma rede intencional anterior a todo ato. O sentido aí vislumbrado não é aquele que um sujeito transcendental configure: ele é imanente ao sensível. Mas ele não é imanente no sentido em que o sensível o traria consigo como que por natureza: esse sentido implica um campo, uma configuração, uma totalidade, horizontes, e é nesse campo que ele significa: cada parte só significa nesse todo, como parte desse todo, como pars totalis. Esses horizontes implicam, por sua vez, um sujeito, mas não aquele sujeito que impõe estruturas ao sensível, ao qual o sensível se submete, e, sim, um sujeito de percepção, um corpo. Esse corpo não se destaca do sensível, à maneira daquela atividade espontânea do sujeito transcendental (husserliano ou kantiano) que nada tem de empírico. O corpo está mais próximo do mundo, ele é feito do mesmo estofo que o mundo, da mesma carne: ele não constitui o sentido do mundo, ele é parte do mundo.

Ora, que isso tem a ver com as artes?

\section{III}

Duas observações e uma tentativa de aproximação entre MerleauPonty e Sartre:

1) A coisa percebida não é um objeto, um $X$ suporte de determinações, de predicações, uma coisa geral, como a cera cartesiana, mas uma coisa sensivel cujo sentido lhe é imanente. A tarefa da filosofia é recuar a esse nível originário de significação, e é por isso que a filosofia se encontra mais próxima das artes do que das ciências. Afinal, a obra de arte (a pintura, a música, por exemplo) não é outra coisa que um todo cujo sentido lhe é imanente: "A significação musical da sonata é inseparável dos sons que a conduzem”: os sons não 
são "signos" da sonata, sonata que estaria então fora deles, mas "ela está ali através deles, ela irrompe neles” (MERLEAU-PONTY, 1995a, p. 213). O sentido é imanente aos signos, cativo deles, isto é, do sensível. A obra de arte é como a coisa percebida: sua significação é cativa do sensível que a veicula, que a apresenta. Diz Merleau-Ponty (1995a, p. 213):

a expressão estética confere a existência em si àquilo que exprime, instala-o na natureza como uma coisa percebida acessível a todos ou, inversamente, arranca os próprios signos - a pessoa do ator, as cores e a tela do pintor - de sua existência empírica e os arrebata para um outro mundo.

Esse "outro mundo" é outro que o mundo da orientação natural e que permanece "ignorado por nós enquanto permanecermos numa postura prática ou utilitária” (MERLEAU-PONTY, 2002, p. 11). Despertar o mundo percebido (esse outro mundo), romper com a orientação natural é reaprender a ver, é restituir ao mundo sua expressividade, é ir além da "visão profana". Esse mundo, somos tentados a ignorá-lo; o mundo de que fala a ciência, o mundo "verdadeiro", ou o mundo da vida prática, está para além desse mundo sensível. É necessário um esforço, de que a pintura é parte, para restituir ao mundo sua expressividade. O paradoxo está nisso: é necessário um esforço para vermos o que mais salta à vista (para retomar aqui um tema caro a Bento Prado Júnior). E a "expressão estética" não realiza senão isso: essa "coisa" expressiva, que não admite substituição: a obra de arte se vê ou se ouve, sua significação exige sua exibição. Sendo assim, a obra não traduz um significado, não remete a um significado que estaria fora dela: ela não é re-presentação, imitação, cópia de um modelo, janela para o mundo. A mimesis não é boa categoria para compreender a obra de arte, assim como também não o é a perfeição.

2) Se não há essa significação fora da obra, que a tornaria então obra de arte, que daria a ela enfim seu valor de obra, então não há, para o artista criador, uma concepção que preceda a execução: se o sentido da obra irrompe dos próprios signos, é do trabalho do artista com os materiais sensíveis de que dispõe que esse sentido irrompe. E aqui a astúcia é a seguinte: se esse sentido irrompe da execução, permanecendo cativo dos signos, então a situação do artista é comparável não à daquele sujeito transcendental, cuja atividade espontânea dá sentido a um material em si mesmo opaco, mas à daquele corpo diante de um sensível categorialmente enformado, cujos laços internos manifestam um Logos imanente. Essa lógica do sensível afasta a ideia do gênio criador, aquele 
que dá regra à arte, para tornar o trabalho de criação, de execução, não o de uma imposição de sentido, mas o de desentranhamento do sentido que habita esse sensível, de início esparso nele, e, pelo trabalho do artista, configurado na obra. Daí a predileção de Merleau-Ponty pelas metáforas do descentramento do artista: o pintor é aquele que começa por contemplar o espetáculo do mundo, mas à força de contemplá-lo, é o espetáculo que começa a se organizar por si mesmo diante dele: Cézanne não pensa a paisagem, mas, como ele mesmo diz, é a paisagem que se pensa nele; entre ele e o visível, as relações se invertem: “em uma floresta”, disse Klee (apud MERLEAU-PONTY, 1996b, p. 31):

várias vezes senti que não era eu que olhava a floresta. Certos dias, senti que eram as árvores que me olhavam, que me falavam... Eu estava ali, escutando... Penso que o pintor deve ser atravessado pelo universo e não querer atravessá-lo... Espero estar inteiramente submerso, sepultado.

Ruminando o mundo, a tarefa do pintor não é outra que a de revelar esse mundo mesmo: não se trata para ele de "falar do espaço e da luz, mas de fazerem falar o espaço e a luz que estão aí" (MERLEAU-PONTY, 1996b, p. 59), isto é, de fazer falar o "Logos das linhas, das luzes, das cores, dos relevos, das massas" (MERLEAU-PONTY, 1996b, p. 71). O artista e o filósofo se consagram ao mesmo Logos, ambos se dão por tarefa retomá-lo e fazê-lo falar, cada um à sua maneira.

3) Por fim, uma aproximação, a propósito desse mesmo tema, entre Merleau-Ponty e Sartre. ${ }^{1}$ Para Merleau-Ponty, de todas as artes, a pintura é aquela que está mais próxima desse mundo originário, não ainda "escondido por todos os sedimentos do conhecimento e da vida social" (MERLEAU-PONTY, 2002 , p. 53). E o pintor está mais próximo "com toda a inocência", como se sua tarefa de "ruminação do mundo" não tivesse outra urgência senão a de revelar esse mundo mesmo, "sem outra 'técnica' senão a que seus olhos e suas mãos oferecem à força de ver, à força de pintar" (MERLEAU-PONTY, 1996b, p. 13-14). O pintor se consagra inteiramente ao visível, ele não faz outra coisa que levar "à sua última potência um delírio que é a visão mesma"

1 Essa aproximação é feita pelo próprio Merleau-Ponty. A partir dela, como de hábito, seu próprio pensamento vai se formando. Isso, de resto, não é um cacoete do filósofo; é constitutivo de seu pensamento, pois sua ontologia indireta requer sempre a mediação daquilo que já está constituído. Daí porque ele parte da ciência, das artes, da história da filosofia, etc. 
(MERLEAU-PONTY, 1996b, p. 26). Diferentemente é o que se passa com o escritor: porque fala, ele atravessa o mundo, ele fala do mundo: ele está além porque ele se serve da linguagem. Ora, não era exatamente isso que dizia Sartre?

O escritor é um falante, um prosador; seu material são os signos, e o que é próprio do signo é reenviar a um significado transcendente: atravessamos as palavras em direção a esse significado, "como o sol ao vidro" (SARTRE, 1989, p. 19). A cor não remete a nada, não significa nada: ela é uma coisa. O escritor, porque lida com signos, e signo remete a significado transcendente, o ultrapassa em direção a esse significado. Deter-se nos signos não é o que propriamente importa a ele, mas visar a isso que ele vai dizer: o escritor se serve das palavras para visar a este isso. Na prosa, o essencial não é o agrado, é a comunicação, isso porque a palavra não é coisa, objeto, mas é "designação de objeto": "não se trata de saber", diz Sartre a respeito da prosa, se as palavras "agradam ou desagradam por si próprias, mas sim se indicam corretamente determinada coisa do mundo ou determinada noção" (SARTRE, 1989, p. 18). Na prosa, a dimensão comunicativa vem antes da dimensão estética. É certo, Sartre reconhece, que é o estilo que determina o valor da prosa; portanto, esse valor não advém daquilo que nela se diz, mas de que nela se diz algo de uma certa maneira. Mas o estilo não é $o$ fim: o estilo é como a etiqueta da missa, ela predispõe para a fé, mas não é a fé, como um tom de voz predispõe para o assunto, mas não é o assunto: a beleza está nesse tom de voz, nessa etiqueta, mas ela não esgota aquilo que se comunica. Em virtude disso, Sartre vai ressaltar o papel proeminente do prosador: se há um significado que transcende as palavras, que está fora delas, então esse significado se sustenta pela intenção de dizer do prosador.

Ora, é diferente o que se passa com a pintura; afinal, o pintor não se serve de cores para dizer alguma coisa, para significar alguma coisa: as cores são mudas, elas nada dizem, não significam angústia, alegria; é sua natureza de coisa que a proíbe de significar, isto é, de reenviar a um significado transcendente. Daí porque Sartre afirme, como Merleau-Ponty, que o sentido de uma melodia (ou de uma tela) não é mais que a própria melodia (ou a tela); ele diz isso em clara oposição à prosa, cujo significado é transcendente e pode, em princípio, ser traduzido de diversas maneiras, por diversas palavras, enquanto o sentido que o vermelho carrega consigo não é outro que aquele exibido por esse vermelho. Uma vez a cor-objeto transportada para a tela, "a única modificação por que [o pintor] a fará passar é transformá-la em objeto imaginário" (SARTRE, 1989, p. 10): o pintor não traça signos na tela, aquele casebre não simboliza a injustiça social, não a significa; é o mau pintor que pinta os tipos 
(o Árabe, a Criança, a Mulher), filas de operários aguardando na neve oferta de trabalho para comover. O bom pintor apenas pinta um casebre, esse casebre é mudo porque as cores são mudas; o espectador, portanto, vê nele o que quiser, ele mesmo nada diz. Na tela, esse casebre não é outra coisa que um casebre imaginário, irreal - a exigir de quem o contempla uma conversão de atitude, pela qual a sua imaginação entra em operação e apreende, a partir daquelas cores pintadas na tela, um objeto estético irreal.

Portanto, é o prosador, não o pintor, que diz algo. Se há um significado transcendente, ele não está nas palavras, como o sentido da tela, inversamente, está nas cores ou da música está nos sons. As palavras apenas designam isso de que falam, e isso de que falam, por sua vez, requer um falante. Ao significado transcendente, corresponde um sujeito falante, um prosador que maneja as palavras em vista, primeiramente, disso que ele quer dizer.

Referindo-se à ideia sartriana da cor-objeto, diz Merleau-Ponty: "o sentido é bem mais que uma 'bruma de calor' na superfície da tela, pois é capaz de exigir essa cor ou esse objeto de preferência a qualquer outro, e porque comanda tais arranjos subordinados tão imperiosamente quanto uma sintaxe ou uma lógica" (MERLEAU-PONTY, 1985, p. 69; 1995b, p. 87, grifo meu). Ora, o que se ressalta aqui para Merleau-Ponty é essa lógica imanente, e é ela que arranca do pintor o traçado realizado, é ela que comanda (daí porque a concepção não precede de modo algum a execução): o pintor não é um demiurgo, ele atende a uma solicitação de um sentido em formação, que é como um polo a exigir cada traçado, e esse sentido nascente é governado por um conjunto aberto, em vias de formação. Não se trata, então, como para Sartre, de dizer que o pintor, ao escolher amarelo e não violeta, "teve motivos, mesmo que ocultos", e que os objetos criados "refletem as suas tendências as mais profundas" (SARTRE, 1989, p. 11). Não há "tendências" em MerleauPonty: a decisão de Matisse, a decisão de Dostoievski (portanto, pintura, literatura...) se assenta nessa lógica, em um "princípio único que prescreve a cada elemento sua modulação" (MERLEAU-PONTY, 1985, p. 71; 1995b, p. 91). A criação não é construída em um laboratório íntimo; ao contrário, o artista é atravessado por uma exigência à qual ele responde criando.

E quanto à literatura? Ora, a propósito das artes de linguagem, Merleau-Ponty, muito mais claramente, vai erguer uma dupla oposição a Sartre, relativa, de um lado, ao polo do significado, de outro, ao polo do prosador. Ele nota de início que a fala não é a tradução de um pensamento já feito, que a palavra não é um invólucro inerte do pensamento. Ao contrário, a fala deve conduzir o pensamento, deve levar consigo a significação: a fala é, não a tradução de 
um pensamento já feito, mas um ato original que a consuma. Ora, é justamente isso que permite a Merleau-Ponty aproximar a fala da pintura e da música: em qualquer dos casos, trata-se de uma operação expressiva que "realiza ou efetua a significação e não se limita a traduzi-la” (MERLEAU-PONTY, 1995a, p. 213). No entanto, no caso das artes de linguagem, sua potência é "menos visível" (MERLEAU-PONTY, 1995a, p. 209): é que, como vivemos em um mundo em que a fala é já instituída, em que há significações já formadas e sedimentadas, o mundo da linguagem nos aparece como "já falado". Daí a "ilusão de já possuirmos em nós, com o sentido comum das palavras, o que é preciso para compreender qualquer texto" (MERLEAU-PONTY, 1995a, p. 209). É a ilusão de que a significação existe para si, antes de ser falada, antes da fala que a produziu. A fala se esquece de si mesma e a significação parece destacar-se dela, isto é, dos signos que a conduzem. Essa virtude da fala de fazer-se esquecer implanta em nós a ilusão do significado para si. Daí a necessidade de distinguir a fala falada da fala falante, aquela fala que desfruta de significações já instituídas daquela que é expressiva, originária, produtora de sentido. Sartre ignora solenemente essa distinção. É isso que permite a ele distinguir tão nitidamente aquilo que o prosador diz, e que se sustenta pela intenção do autor, da maneira pela qual ele diz. É isso que permite a Sartre afirmar que o objeto literário só existe pelo leitor e na medida dos esforços do leitor: "fora [da leitura] há apenas traços negros sobre o papel" (SARTRE, 1989, p. 35). Tudo se passa como se a obra, objeto inerte, dependesse da animação do leitor, que a põe em movimento e a faz significar. Fui eu que animei esses traços negros sobre o papel, fui eu, leitor, que os fiz viver e dizer alguma coisa, fui eu que fiz o fogo "pegar". Ora, diz Merleau-Ponty, é certo que "eu, leitor, posso ter a impressão de ter criado o livro de ponta a ponta. Mas, enfim, isso só acontece depois" (MERLEAU-PONTY, 1995b, p. 17): é apenas retrospectivamente que terei a ilusão de tê-lo criado, de que dispunha de tudo o que era preciso para criá-lo. Durante a leitura, passou-se algo diferente do que supõe Sartre, e que é de mesma natureza daquele descentramento de que falávamos a respeito do pintor: se, para ler esse livro, eu trouxe comigo meu conhecimento da língua, "aos poucos, imperceptivelmente, o autor desvia os signos de seu sentido ordinário, e estes me arrastam como um turbilhão para um outro sentido que eu vou encontrar" (MERLEAU-PONTY, 1995b, p. 18-19). E, ainda uma vez, se esse descentramento só ocorrer, é porque há uma lógica interna à linguagem, porque ela se compõe e se organiza consigo mesma, é porque o artista encontra ali um Logos, tal como o pintor também o encontrou diante do mundo. Em nenhum dos casos, a criação remonta a um sujeito como a sua origem; antes disso, é a própria obra ou o sentido em vias de 
formação que solicita ao sujeito os gestos necessários para que ele venha a ser: aqui, é o sujeito que segue o curso da expressão, como se estivesse investido e envolvido por ela, não o inverso: "da mesma forma que a operação do corpo, a das palavras ou das pinturas me permanece obscura: as palavras, os traços, as cores que me exprimem saem de mim como os meus gestos, são-me arrancados pelo que quero dizer como os meus gestos pelo que quero fazer. Nesse sentido, há em toda expressão uma espontaneidade que não se submete a regras, nem mesmo àquelas que eu gostaria de dar a mim mesmo" (MERLEAU-PONTY, 1985, p. 94; 1995b, p. 122).

Ora, essas diferenças entre Merleau-Ponty e Sartre parecem ocultar uma diferença mais profunda, no nível da ontologia. Pois, se é verdade que na obra de arte o sentido é imanente aos signos (a significação pictórica é imanente à tela, a significação musical da sonata é inseparável dos sons que a conduzem), é verdade também que isso aproxima a obra de arte da coisa percebida ("é impossível", diz Merleau-Ponty, "separar as coisas e sua maneira de aparecer" (MERLEAU-PONTY, 2002, p. 54): em ambos os casos, mesma imbricação entre signos e significado, entre maneiras de aparecer e significação. Ora, para Sartre, o objeto estético pictórico ou musical é, inversamente, um objeto irreal. Tudo se passa, para Merleau-Ponty, como se a definição sartriana do ser fosse tal que ele não pudesse comportar essas maneiras, e por isso, para ele, Sartre tivesse que lançá-las na conta exclusiva de um para-si diante de um em si massivo. Daí a consequência no plano estético: o objeto estético não é objeto real, ele está fora desse mundo, ele é puramente imaginário. Para Merleau-Ponty, ao contrário, o ser envolve de tal modo o inaparente, o invisível, aquelas maneiras irreais, "imagens", que a obra de arte é tomada por ele não como o outro do ser, mas como um emblema dele: é o ser ele mesmo configurado na obra: "[...] profundidade, cor, forma, linha, movimento, contorno, fisionomia são ramos do Ser, e cada um deles [traz] consigo toda a ramagem" (MERLEAU-PONTY, 1996b, p. 88). A pintura vai se definindo, portanto, como uma via real de acesso ao ser, de acesso ao "imaginário" - ou, melhor ainda, de acesso a um Ser que está para além da distinção entre imagem e percepção - e, se é assim, é porque o ser ele mesmo comporta "imagens", "irrealidades", invisíveis, é porque ele foi definido em sentido fenomenológico, em que ser e maneiras de ser se imbricam. Daí porque Merleau-Ponty vai definir a pintura como uma "ciência secreta" (MERLEAU-PONTY, 1996b, p. 15).

Resta o difícil problema da linguagem. Não é o caso aqui, nesse curto trabalho, de mostrar todas as mediações que levam à imbricação entre 
mundo e linguagem. Basta dizer que o núcleo da questão consistirá em romper a distinção entre sentido mudo e sentido linguageiro, em mostrar que o silêncio não é "o contrário da linguagem", que o mundo do silêncio envolve a fala e que, portanto, ele é já “o mundo articulado" (MERLEAU-PONTY, 1996c, p. 233). Isso permite superar a tese sartriana da proeminência do prosador em sentido mais radical do que o permite uma fenomenologia da linguagem, que apenas desloca o sentido para a fala falante. É só então que a ontologia indireta pode assumir plenamente um novo estatuto para as artes, sejam as artes mudas, sejam as artes linguageiras.

\section{Referências}

BARBARAS, R. De l'être du phénomène. Sur l'ontologie de Merleau-Ponty. Grenoble: Jérôme Million, 1991.

HEIDEGGER, M. Prolegomena zur Geschichte des Zeitbegriffs. Band 20. Frankfurt: Vittorio Klostermann, 1979.

MERLEAU-PONTY, M. Signes. Paris: Gallimard, 1985.

MERLEAU-PONTY, M. Phénoménologie de la perception. Paris: Gallimard, 1995a. MERLEAU-PONTY, M. La prose du monde. Paris: Gallimard, 1995b.

MERLEAU-PONTY, M. Notes de cours. Paris: Gallimard, 1996a.

MERLEAU-PONTY, M. L'œil et l'esprit. Paris: Gallimard, 1996b.

MERLEAU-PONTY, M. Le visible et l'invisible. Paris: Gallimard, 1996c.

MERLEAU-PONTY, M. Causeries. Paris: Seuil, 2002.

SARTRE, J.-P. Que é a literatura? São Paulo: Ática, 1989.

Recebido: 28/07/2010

Received: 07/28/2010

Aprovado: 09/09/2010

Approved: 09/09/2010 